\title{
Perancangan Security Sistem Jaringan Berbasis Untangle Firewall pada Unisadhuguna International Education
}

\author{
Haris Mauludin ${ }^{a 1}$, Herman Kuswanto ${ }^{a 2}$ \\ ${ }^{a}$ Faultas Teknologi Informasi, Universitas Nusa Mandiri \\ Jalan Jatiwaringin Raya, Kecamatan Makasar, Jakarta Timur 13620 \\ ${ }^{1}$ harismauludin200@gmail.com \\ 2herman.hko@nusamandiri.ac.id
}

\begin{abstract}
Abstrak
Pada sebuah sistem jaringan komputer sudah pasti tidak lepas dari sebuah permasalahan yang sering terjadi, begitu juga pada Unisadhuguna yang telah terjadi beberapa masalah pada sistem jaringan komputernya baik dari sistem atau dari user (pengguna). Permasalahan yang terjadi pada user adalah akses full jaringan internet yang didapat sering kali malah digunakan untuk beberapa hal yang diluar batas pekerjaan, sering digunakan untuk mengakses sebuah website yang bisa membuat pekerjaan menjadi terbengkalai bahkan sampai mengakses sebuah website yang berbau dengan ponograpi, permasalahan lainnya adalah kurang efektifnya sistem jaringan komputer yang berjalan. Untuk mengatasi permasalahan diatas, dilakukan sebuah penelitian untuk memperbaiki sistem jaringan komputer yang berjalan diatas, dengan diusulkan menggunakan sebuah keamanan jaringan komputer berbasis aplikasi Untangle dan merubah skema jaringan komputer yang sedang berjalan pada Unisadhuguna. Dengan menggunakan metode kemanan jaringan hasil yang didapatkan nanti oleh setiap komputer adalah akses internet yang di atur oleh aplikasi Untangle, dan hasilnya nanti sistem keamanan jaringan komputer akan memfilter dan memblock sebuah aplikasi yang sering digunakan oleh user yang tidak berhubungan dengan pekerjaan.
\end{abstract}

Kata kunci : Jaringan Komputer, Untangle, Client

\section{Design of security network system based on untangle firewall in unisadhuguna international education}

\begin{abstract}
In a computer network system, it is definitely not free from a problem that often occurs, as well as in Unisadhuguna where several problems have occurred in the computer network system either from the system or from the user. The problem that occurs to the user is that the full access to the internet network that is obtained is often used for several things that are outside the work limit, often used to access a website that can make work neglected even to access a website that smells of ponography, other problems are less the effectiveness of the running computer network system. To overcome the above problems, a study was carried out to improve the computer network system that was running above, it was proposed to use a computer network security based on the Untangle application and change the computer network scheme that was running on Unisadhuguna. By using the network security method, the results obtained later by each computer is internet access which is regulated by the Untangle application, and the result is that the computer network security system will filter and block an application that is often used by users who are not related to work.
\end{abstract}

Keywords: Computer Network, Untangle, Client

\section{Pendahuluan}

Pada saat ini semakin pesatnya perkembangan teknologi dan semakin banyak orang yang bisa mengakses layanan internet dengan mudah, dimanapun serta kapanpun, dengan kemudahan itu semua orang bisa dengan gampang mendapat sebuah informasi apapun, namun dibalik kemudahan itu semua pasti ada dampak positif dan negatifnya. Contohnya sebuah kasus pada salah satu perusahaan yang akan penulis angkat disini, dimana setiap staff atau karyawan bisa dengan bebas mengakses internet kapanpun dan dimanapun selama masih berada di wilayah perusahaan, hal ini dikarenakan tidak adanya sistem keamanan dari jaringan yang berjalan di perusahaan tersebut. Bukan sebuah masalah kecil tidak adanya sistem keamanan jaringan justru ini masalah yang cukup besar karena akan berdampak juga pada perusahaan tersebut. Sebuah keamanan jaringan tidak hanya terdiri 
dari satu aspek saja, melainkan mengandung empat aspek tautan yang penting yaitu perangakat keras, perangkat lunak, jaringan dan layanan internet serta sumber daya bersama. Menurut definisi sebuah keamanan jaringan komputer sebenarnya mengacu pada perlindungan perangkat lunak, perangkat keras, serta sumber daya data [1].

Sebuah keamanan jaringan tidak hanya terdiri dari satu aspek saja, melainkan mengandung empat aspek tautan yang penting yaitu perangakat keras, perangkat lunak, jaringan dan layanan internet serta sumber daya bersama. Menurut definisi sebuah keamanan jaringan komputer sebenarnya mengacu pada perlindungan perangkat lunak, perangkat keras, serta sumber daya data [1]. dalam membangun sebuah keamanan jaringan komputer tidak hanya menjaga dari serangan dari internet, pengunaan tidak bijak dari user tetapi juga menerapkan konfigurasi untuk mencegah terjadinya sebuah kesalahan. Contohnya seperti penerapan konfigurasi anti rouge DHCP, yang terkadang sering terjadi karena disebabkan penambahan sebuah perangkat pada salah satu client yang tanpa diketahui oleh server atau komputer administrator [2]. Keamanan jaringan komputer adalah salah satu bagian dari sebuah informasi, sangat begitu penting untuk majaga setiap validitas dan integritas. Sistem harus dijaga dan dilindungi dari berbagai segala macam bahaya penyusupan dan serangan serta pemindaian baik itu sebuah serangan dari dalam maupun dari luar system [3].

Ada beberpa cara atau solusi yang dapat digunakan untuk mengatasi sebuah masalah seperti ini, contohnya bisa menggunakan sebuah firewall, firewall adalah sebuah teknik penting dan sangat berguna untuk mengamankan sebuah jaringan komputer, firewall juga merupakan salah satu sistem mekanisme atau suatu model yang bisa di terapkan pada perangkat hardware, software ataupun pada sebuah sistem perangkat itu sendiri yang bertujuan untuk memfilter, melindungi sampai menolak semua hubungan dari beberapa perangkat jaringan computer [4], firewall jga merupakan sebuah komponen atau sekumpulan komponen yang membatasi sebuah akses jaringan yang diproteksi dan terhubung ke internet atau beberapa kumpulan jaringan lainnya. Firewall merupakan salah satu solusi untuk membuat keamanan didalam dunia internet baik dalam keamanan jaringan maupun komputer yang mempunyai berbagai macam ancaman, dengan satu konfigurasi yang benar pada firewall maka setiap data atau informasi akan jauh lebih aman, Cara lain untuk membuat keamanan sebuah jaringan adalah dengan menggunakan sebuah apalikasi yang bernama Untangle Firewall. Untangle merupakan sebuah aplikasi keamanan jaringan yang bisa digunakan pada sebuah jaringan komputer untuk mencegah, menangani dan menjaga sebuah spam blocker, spyware blocker, phish blocker, protocol control dan intrusion prevention, untangle ini merupakan sebuah aplikasi turunan dari Debian [5]. Untangle Firewall juga sebuah apalikasi jaringan yang berbasis open source dan sudah teritegrasi dengan modul untuk memfilter [6].

\section{MetodoloGI}

\section{A. Kerangka Makalah}

Untuk dapat memperoleh data bahan yang dibutuhkan oleh penulis, disini penulis menggunakan beberapa metode penelitian untuk menjadi acuannya, diantaranya:

1) Observasi: Disini dilakukan pengamatan secara langsung jaringan pada Unisadhuguna International Education untuk mengumpulkan semua informasi pada sistem jaringan yang sedang berjalan.

2) Wawancara: Disini dikumpulkan informasi atau data keadaan suatu jaringan komputer dengan cara mewawancarai secara langsung kepada berbagai orang atau pihak yang terkait pengelolaan sistem jaringan yang ada pada Unisadhuguna International Education.

3) Studi Pustaka: Didalam studi pustaka ini akan dilakukan pengumpulan informasi atau data yang sangat berkaitan erat dengan berbagai masalah yang ada pada penelitian ini bersumber dari jurnal - jurnal yang berkaitan dengan permasalahan yang ada.

\section{B. Analisis Perancangan}

1) Studi Pustaka: Analisa disini dilakukan meliputi model topologi apa yang sedang berjalan atau digunakan sekarang, spesifikasi dari perangkat dan apa permasalahan yang sering terjadi. Dari hasil yang sudah didapat bisa menjadi acuan atau tolak ukur bagi kebutuhan untuk memberikan solusi dari permasalahannya.

2) Desian: Pada proses ini akan dirancang sebuah sistem jaringan komputer, berdasarkan dari hasil penganalisaan kebutuhan jaringan komputer diatas. Desain dan rancangannya meliputi metode topologi jaringan komputer, perangkat yang dibutuhkan dan protocol jaringan.

3) Testing: Pada tahap ini, akan dilakukan proses percobaan agar sistem jaringan komputer yang baru dapat disesuaikan dengan rancangan yang telah dibuat serta dilakukan analisa jika terjadi problem sebelum diterapkan pada jaringan tersebut. Disini juga akan dilakukan simulasi percobaan dengan menggunakan software simulator.

4) Implementasi: Pada proses implementasi ini sistem jaringan yang baru akan langsung diterapkan pada sistem jaringan komputer Unisadhuguna International Education, serta langsung di uji coba oleh pihak yang terkait.

\section{HASIL DAN PERANCANGAN}

Melihat permasalahan dan problem yang terjadi, yang begitu sangat mempengaruhi kinerja dan hasil bagi perusahaan, maka sangat penting sekali untuk dibangunnya sistem keamanan jaringan komputer. Untuk alternative pemecahan masalah agar dapat menanggulangi problemnya maka akan di bangun sebuah keamanan jaringan komputer dengan menggunakan aplikasi Untangle, diamana nantinya setiap ip address komputer yang sering terjadi problem akan di atur akses jaringannya dengan di filter atau di blocking ke beberapa alamat 
website yang dianggap menggagu kinerja pekerjaan, dengan memanfatkan fitur blocking pada aplikasi

Untangle. Fungsi dari aplikasi Untangle ini adalah untuk memfilter dan memblocking akses internet dari setiap komputer serta memblocking juga salah satu website agar tidak bisa di akses oleh user.

\section{A. Jaringan Usulan}

Pada jaringan usulan disarankan beberapa usulan perubahan untuk sistem jaringan komputer dan sistem keamanan di Unisadhuguna guna mencegah beberapa masalah dan problem yang pernah terjadi beberapa waktu lalu di Unisadhuguna. Disini akan mencoba untuk merubah dari segi skema dan topologi jaringan berjalan, dengan menambahan Pc Untangle dan konfigurasi firewall menggunakan untangle yang digunaan untuk membatasi akses ke internet.

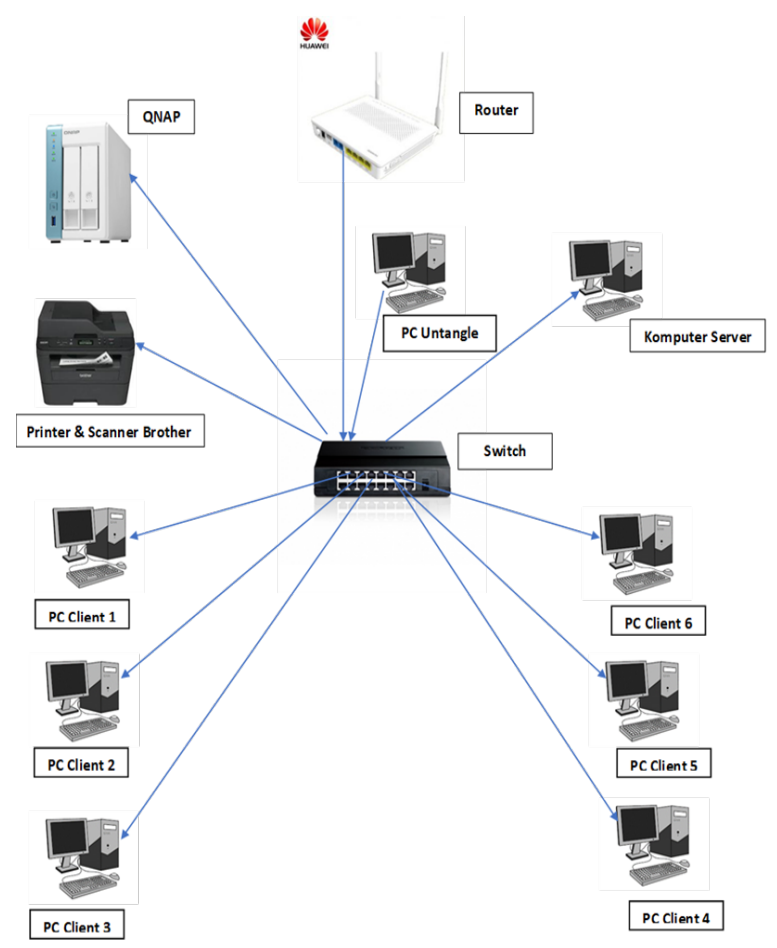

Gambar 1. Topologi Usulan

\section{B. Rancangan Aplikasi}

Pada perancangan aplikasi ini, sistem kemanan menggunakan firewall Untangle akan dijadikan sistem keamanan jaringan komputer pada Unisadhuguna. Untuk perancangan aplikasinya satu unit komputer akan dijadikan sebagai server dari Untangle, karena untuk menggunakan aplikasi ini sistem operasi dari komputer tersebut harus di install menggunakan aplikasi Untangle ini. Cara kerja dari aplikasi Untangle ini untuk dijadikan firewall adalah dimana nantinya Untangle ini akan bertugas untuk memfilter atau memblocking sebuah website memlalui fitur aplikasi filter web yang berada di dalam administrator Untangle tersebut.

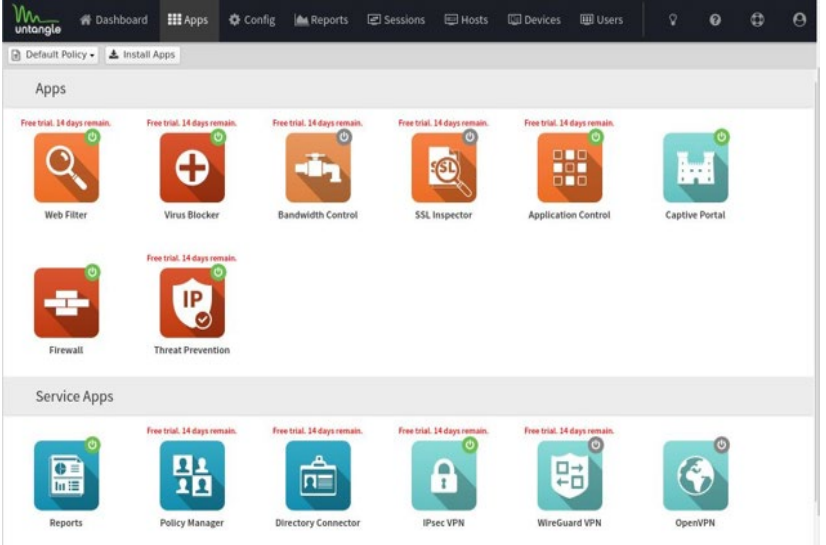

Gambar 2. Menu Pada Untangle

Konfigurasi web filter pada Untangle.

- Masuk kedalam website administrator aplikasi Untangle, dan pasang atau install fitur "Web Filter" pada menu Apps.

- Setelah di pasang lalu masuk ke aplikasi web filter dan pilih tab categories

- Lalu tinggal di pilih menu atau kategori apa yang ingin kita block atau tandai

- Pada langkah ini categories yang dipilih adalah website dengan categories news atau berita, jadi setiap website yang berhubungan dengan berita akan di block.

- Kemudain pilih block untuk memblock dan flag untuk mengetahui sumber user yang ingin mengakses website tersebut

- Untuk memastikan bisa masuk ke tab menu site lookup dan masukan website yang akan di cek categoriesnya.

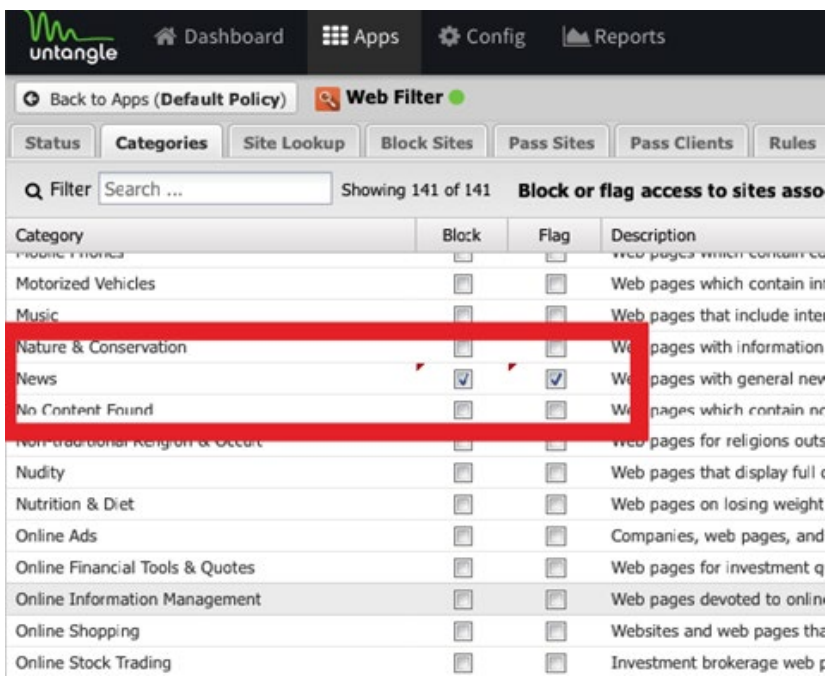

Gambar 3. Menu Web Filter Untangle

Konfigurasi dan cara mengaktifkan menu Firewall pada Untangle

- Masuk ke dalam menu administrator atau menu dashboard pada aplikasi Untangle.

- Kemudian pilih menu Aplikasi dan Install atau pasang fitur firewall. 
- setelah di install dan pasang baru nyalakan fitru firewall tersebut.

- Setelah selesai di aktifkan, kita langsuk masuk ke langkah menambah rules untuk memblock dan flag.

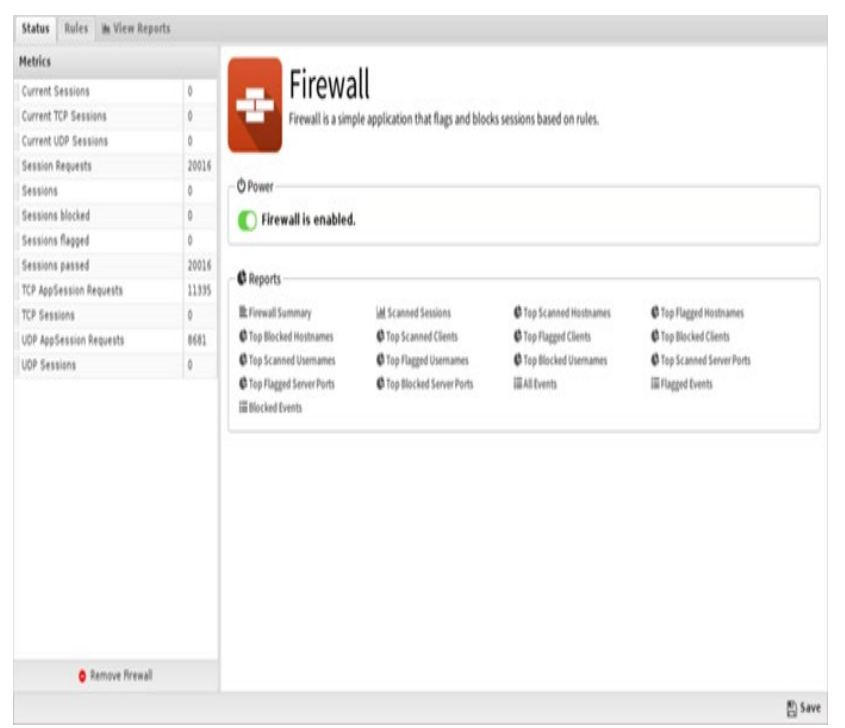

Gambar 4. Fitur aplikasi firewall pada Untangle

- Setalah itu tingga di centang rules yang akan di pilih dan save, maka fitur firewall pada aplikasi Untangle sudah aktif.
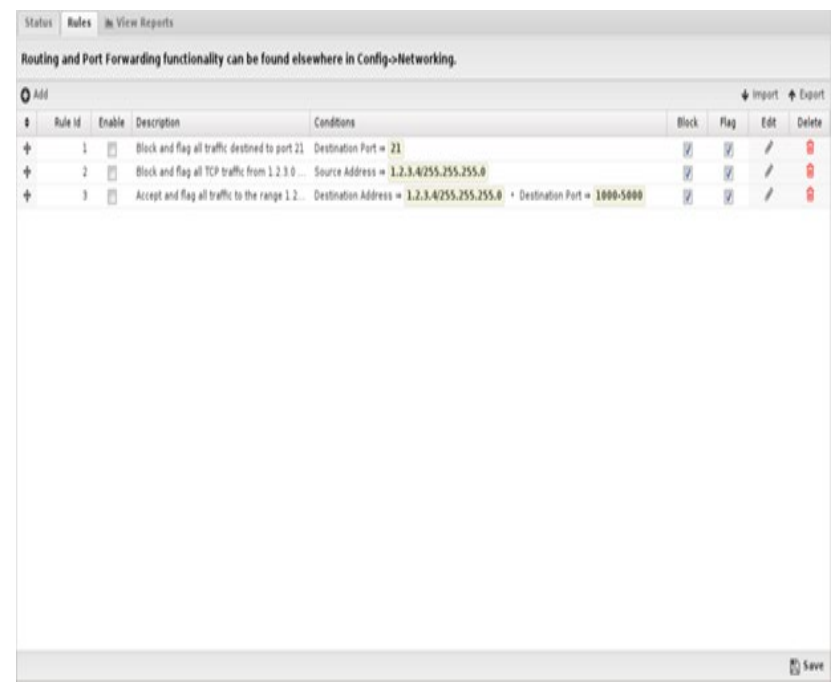

Gambar 5. Menu rules firewall Ungtangle

\section{Pengujuain Jaringan}

Pada tahap pengujian jaringan disini akan di lakukan pengujian pada pc client dimana pengujiannya dengan menguji akses internet dari komputer client apakah masih bisa atau tidak mengakses website yang sudah diblok dari Untangle dengan memfilter dan meblocking sebuah website.

\section{Pengujian Awal}

Pengujian awal dilakukan bertujuan untuk mengoreksi dan simulasi perancangan ususlan yang sudah di terapkan pada sistem jaringan komputer, hasil dari pengujian awal ini bertujuan untuk membuktikan sebelum terpasangnya sistem keamanan jaringan menggunakan aplikasi Untangle. Pada pengujian awal ini dilakukan dengan cara mengakases ke situs berbagi video https://www.youtube.com, dari pengujian dihasilkan situs dapat terbuka dengan lancar, itu disebabkan belum adanya firewall pada jaringan yang dapat membatasi akses ke situs -situs yang tidak diinginkan.

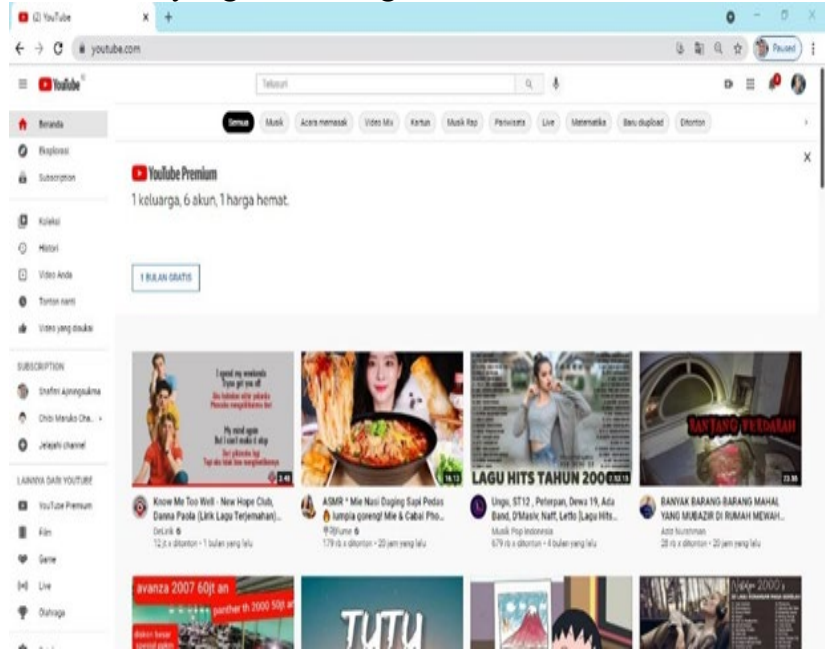

Gambar 6. Hasil pengujian awal

\section{Pengujian Akhir}

Pada pengujian akhir ini akan dilakukan dengan semua perangkat jaringan dan skema jaringan yang telah di terapakan dari jaringan yang telah diusulkan. Pengujian dilakukan setelah dilakukan konfigurasi firewall pada untangle yaitu dengan memblok suatu website yang tidak diinginkan diakses saat bekerja, firewall tersebut diterapan pada semua pc client yang terkoneksi ke jaringan. Dari hasil pengujian yang dilakukan pc client yang terkoneksi ke jaringan saat membuka situs yang sudah diblok pada firewall situs tidak dapat terbuka dengan sempurna, ini disebaban situs tersebut masuk ke daftar situs yang tidak diijinkan untuk diakses saat bekerja, dengan kesimpulan konfigurasi firewall pada untangle yang telah diaktifkan bekerja dengan baik.

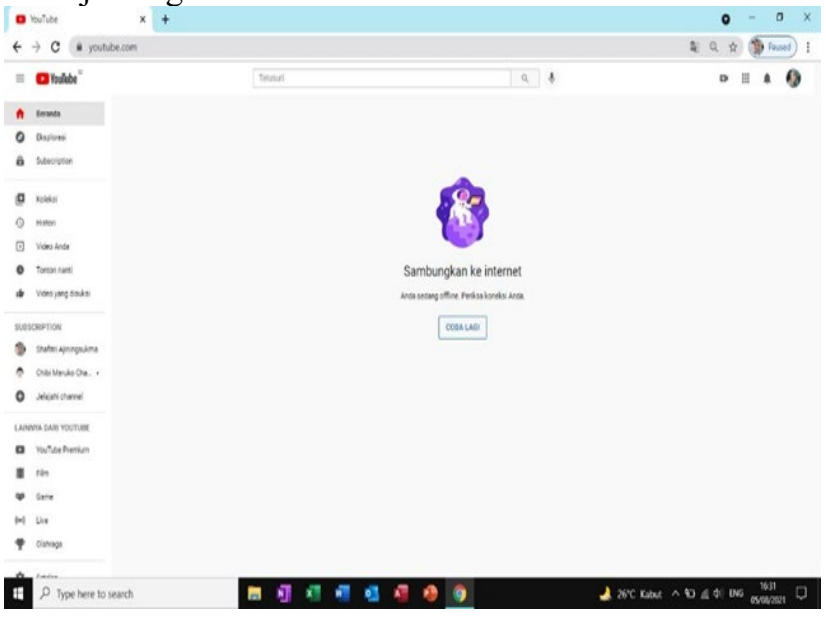

Gambar 7. Hasil pengujian akhir 


\section{KESIMPULAN}

Berdasarkan dari hasil penelitian dan permasalahan yang ada pada sistem jaringan komputer di Unisadhuguna, disimpulan bahwa dengan diimplementasikanya security jaringan menggunakan firewall untagle, penggunaan akses internet bisa terkontrol dan akses ke situs - situs yang menggangu kinerja karyawan dapat diblok dengan baik menggunakan firewall untangle, dengan penerapan ini kinerja jaringan lebih efektif untuk menunjang kinerja setiap karyawan yang ada.

\section{DAFTAR PUSTAKA}

[1] N. I. Munawar, Zen and Putri, "Keamanan Jaringan Komputer Pada Era Big Data," J-SIKA| J. Sist. Inf. Karya Anak Bangsa, vol. 02, no. 01, pp. 14-20, 2020.

[2] S. A. Pamuji, C. Iswahyudi, and T. Informatika, "Analisis Dan Optimasi Dari Simulasi Keamanan Jaringan Menggunakan Firewall Mikrotik Studi Kasus Di Taman Pintar Yogyakarta," $J$. JARKOM, vol. 7, no. 1, pp. 65-75, 2020 .

[3] M. C. J. Erick et al., “No 主観的健康感を中心とした在宅高齢 者における健康関連指標に関する共分散構造分析 Title,” Rev. CENIC. Ciencias Biológicas, vol. 152, no. 3, p. 28, 2016, [Online]. Available: file:///Users/andreataquez/Downloads/guiaplan-de-mejora

institucional.pdf\%0Ahttp://salud.tabasco.gob.mx/content/revista $\%$ 0Ahttp://www.revistaalad.com/pdfs/Guias_ALAD_11_Nov_2013 .pdf\%0Ahttp://dx.doi.org/10.15446/revfacmed.v66n 3.60060.\%0A http://www.cenetec.

[4] Sugiyono, "Sistem keamanan jaringan komputer menggunakan metode watchguard firebox pada pt guna karya indonesia," $J$. CKI, vol. 9, no. 1, pp. 1-8, 2016.

[5] P. Blocker, S. Blocker, W. Filter, V. Blocker, I. Prevention, and P. Control, "5/24/2021 Untangle | Hendra Manto Sitorus," pp. 5-7, 2021.

[6] F. Adhi Purwaningrum, A. Purwanto, E. Agus Darmadi, P. Tri Mitra Karya Mandiri Blok Semper Jomin Baru, and C. -Karawang, "Optimalisasi Jaringan Menggunakan Firewall," vol. 2, no. 3, pp. $17-23,2018$ 